\title{
Factores que permiten impulsar el uso de franquicias exitosas en Nuevo León
}

\author{
Factors that allow promoting the use of successful franchises in Nuevo León
}

\begin{tabular}{|c|c|}
\hline & $\begin{array}{l}\text { Rodríguez Guerrero Bárbara Beatriz }{ }^{\mathbf{1}} \\
\text { (iD) https://orcid.org/0000-0002-2044-4106 }\end{array}$ \\
\hline & Ayala Palacios Roberto ${ }^{2}$ \\
\hline (c) $(\mathrm{i})(9$ & $\begin{array}{r}\text { Universidad Autónoma de Nuevo León, México } \\
\text { doi https://doi.org/10.29105/pgc6.12-13 }\end{array}$ \\
\hline
\end{tabular}

\section{RESUMEN}

El crecimiento que ha tenido el modelo de franquicia ha sido significativo, debido entre otras razones, al creciente deseo de los individuos por lograr su independencia laboral y económica, por lo que es visto por las empresas como una oportunidad de expansión a otros mercados (Mosquera, 2010). Por lo tanto, lo que se pretende identificar son aquellos factores que impulsan el uso de franquicias exitosas en México, específicamente en Nuevo León, lo cual se puede ver reflejado en un aumento en unidades franquiciadas. Una vez identificados esos factores se podrán promover con las demás empresas, en especial a las PYMES, con deseos de expandirse y que no están integradas a un sistema de franquicias, contribuyendo así a un crecimiento empresarial que impactaría al crecimiento económico del país. La metodología empleada en la investigación fue cuantitativa ya que se pretende recoger datos de una muestra y de ahí poder identificar algunas variables, la recopilación de datos seria a través de un cuestionario que se elaboro a partir del marco teórico revisad, dicho instrumento fue aplicado a una muestra representativa de franquiciadores para conocer los factores que les han permitido tener éxito en sus franquicias y los resultados muestran que uniendo la información de los franquiciadores se identifica que todos coinciden en que el "Renombre de la Marca" influye de manera importante en el éxito de la franquicia, esto reflejado con un aumento en unidades.

Palabras claves: Asistencia Tecnica, Condiciones Contractuales , Franquicias, Relacion de las partes ,Renombre de la marca

\section{ABSTRACT}

The growth of the franchise model has been significant, due, among other reasons, to the growing desire of individuals to achieve their labor and economic independence, which is why companies see it as an opportunity to expand to other markets (Mosquera, 2010). For what is intended to identify those factors that drive the use of successful franchises in Mexico, reflected in an increase in franchised units. For what is intended to identify those factors that drive the use of successful franchises in Mexico, reflected in an increase in franchised units. Once these factors are identified, they can be promoted with other companies, especially SMEs, with a desire to expand and that are not integrated into a franchise system, and thus obtain business growth that would impact the country's economic growth. The methodology used in the research was quantitative since it is intended to collect data from a sample and from there to be able to identify some variables, the data collection would be through a questionnaire that was developed from the revised theoretical framework, said instrument was applied to A representative sample of franchisors to find out the factors that have allowed them to be successful in their franchises and the results show that by combining the information of the franchisors, it is identified that they all agree that the "Renown of the Brand" has an important influence on success of the franchise, this reflected with an increase in units.

Keywords: Technical Assistance, Contractual Conditions, Franchises, Relationship of the parties, Renown of the brand

Recibido: 27 de Noviembre 2019 - Aceptado: 30 de Enero 2020 - Corregido: 28 de Abril 2020

Cómo referenciar este artículo:

Rodriguez Guerrero, B., B. \& Ayala Palacios, R. (2020). Factores que permiten impulsar el uso de franquicias exitosas en nuevo león. Politica Globalidad y Ciudadanía, 246-264. Recuperado de http://revpoliticas.uanl.mx/index.php/RPGyC/ article/view/164

\footnotetext{
1 Profesora e Investigadora de tiempo completo de la Facultad de Ciencias Políticas y Relaciones Internacionales. Universidad Autónoma de Nuevo León. PhD en Filosofía con Orientación en Relaciones Internacionales, Negocios y Diplomacia. Tel oficina 818294000 ext. 2258 , Cel. 8110519834, barbara.rodriguezgro@uanl.edu.mx,

2 Profesor de Tiempo Completo de la Facultad de Ciencias Políticas y Relaciones Internacionales, Universidad Autónoma de Nuevo León. Maestría en Ciencias Políticas. Línea de investigación Responsabilidad Social, Tel. oficina 8183294000 ext. 2962, Cel. 8115003224, Monterrey, Nuevo León, México. roberto.ayalap@uanl.mx
} 


\section{1.- INTRODUCCION}

Los sistema de franquicias están siendo objeto de estudio en la literatura como consecuencia, entre otros aspectos, de la gran importancia que han adquirido en los últimos años como modelo de expansión siendo trascendentales sus implicaciones económicas en el mercado (Fernández y Martin, 2006). Este mecanismo ha venido despertando el interés entre los estudiosos de la economía empresarial, debido a que ha sido una estrategia que se ha consolidado para facilitar la expansión internacional de las empresas (Ulloa, 2012).

Podemos decir que las franquicias es un formato de negocio que permite la expansión de una empresa ya probada, y que mediante un contrato se puede fijar una relación con derechos y obligaciones para cada una de las partes involucradas. Dado que la franquicia son un modelo de desarrollo empresarial que han alcanzado un elevado grado de madurez en el mundo, esto se debe a que resulta ser una forma atractiva de organización corporativa para las empresas que desean expandirse rápidamente con una inversión baja de capital, y un control adecuado de sus procesos de distribución (Erramilli, 2002).

Los estudios estadísticos señalan que las franquicias aparecen como alternativa de negocio atractiva, por que como lo señala la Asociación Mexicana de Franquicias, la supervivencia de estas empresas supera los 5 años, comparado con las otra PYMES que tienen un bajo nivel de supervivencia de 2 a 3 años. Lo mismo señala la Secretaría de Economía, en México el 95\% de las empresas franquiciadas sobreviven al menos a su quinto año de operación (SE, 2014). Es así que aparece como una muy buena alternativa de negocio ante el bajo nivel de supervivencia de las PYMES mexicanas.

A pesar de que las franquicias han crecido y son un modelo de negocios importante, se genera un problema al no contar con la información suficiente para saber cómo crear franquicias exitosas, razón por la cual es importante analizar y evaluar la factibilidad de establecer franquicias en México de cualquier giro. Si se logra identificar aquellos factores que permiten impulsar el uso de franquicias exitosas y se hacer énfasis en esos aspectos claves del negocio, como lo señala Aguirre (2006) se pudiera tener un poco más de ceretza que sera un negocio con éxito.

Por lo que de manera específica, la pregunta de investigación de este proyecto es: ¿Cuáles son los factores que permiten impulsar el uso de franquicias exitosas en Nuevo León?, y como objetivo principal se pretende identificar esos factores que permiten que más franquicias mexicanas tengan éxito. De tal, forma que aquel emprendedor que decida adquirir una franquicia o aquel empresario que vea factible expandise por medio de franquica, cualquiera que sea el giro, pueda conocer desde un inicio aquellos variables o factores que no puede pasar por alto y que le van a garantizar éxito, el cual se vera reflejado con un aumento en ventas y en unidades. Como

Revista Política, Globalidad y Ciudadanía, Vol. 6. No. 12, Julio - Diciembre 2020, Universidad Autónoma de Nuevo León, Monterrey, México, ISSN 2395-8448. 246-264. http://revpoliticas.uanl.mx/index.php/RPGyC/article/view/164 
hipótesis se señala que los factores que permiten impulsar el uso de franquicias exitosas son: la asistencia técnica, la relación de las partes, la antigüedad de la franquicia, las condiciones contractuales y el renombre de la marca.

\section{2.- METODOLOGÍA}

El enfoque dominante de la investigación se desarrollar sobre una perspectiva del enfoque cuantitativo, ya que como lo menciona Aguirre, 2006 el método cuantitativo, según el modelo "racionalista" surge como una necesidad del ser humano por aprender sobre los fenómenos que ocurren a su alrededor y sus relaciones de causa y efecto, con el fin de poder interferir en ellos o utilizar este conocimiento a su favor . En base al marco teórico se logró identificar las variables que han permitido un mayor éxito en las franquicias logrando un un aumento en ventas y en unidades y con ello se elaboró un instrumento para medir variables: Asistencia técnica la relación de las parte), antigüedad de la cadena de franquicias, condiciones contractuales y el renombre de la marca .

Los principales actores en esta investigacion fueron los franquiciadores con franquicias en México , que estaban dentro del Expo Franquicia-T evento donde cada año se reúnen distintas franquicias para dar a conocer su negocio así como los requisitos para ser franquiciatarios de la difrentes franquicia que se presentan en la expo.

Para la selección de la muestra se buscaron franquiciadores con ganas de expandirse y que mejor que aprovechae el punto de reunión de la expo franquicia 2016, realizada en Monterrey, Nuevo León con una asistencia total de 70 franquicias presentes todas de diferentes giros, de las cuales se entrevistaron a 26 de manera aleatoria y se capturaron los resultados en el paquete estadístico SPSS, lo cual ayudo a obtener los resultados de la investigación.

\section{Las principales franquicias en México}

En México se dificultó la entrada de franquicias debido a la política de fronteras cerradas y a la falta de una regulación legal en lo que se refiere a la protección industrial. Es hasta la década de los 80 cuando surge esta modalidad gracias a la creación del Instituto Mexicano de la Propiedad Industrial (IMPI) quien es el responsable de regular a las franquicias en este país, ante él se solicita la inscripción de los Contratos de Franquicia que involucren el uso de marcas o asistencia técnica (INEGI, 2009).

De acuerdo con la revista Entrepreneur, las primeras marcas mexicanas en franquiciar fueron Dormimundo y Sushi itto desde 1989, mismo año en que nació la Asociación Mexicana de 
Franquicias (AMF). Ya para el año de 1994 la AMF contabilizo 457 marcas - en su mayoría extranjeras, aunque también, para el mismo año ya había franquicias mexicanas en el extranjero, por ejemplo; Helados Holanda y Bing, VIPS, Flash Taco y Juven's. En el mismo año de 1995 instituciones como Bancomer, BNCI, Nafin, Bancomext y Fidec la gerencia estaba especializada en franquicias brindaban préstamos a interesados en el modelo de negocios, lo que daba una imagen positiva hacia este model negocio.

Incluso durante la crisis económica del sector restaurantero, la Cámara Nacional de la Industria de Restaurantes y Alimentos Condimentados (CANIRAC, 2014) señaló que más de 5,000 restaurantes cerraron sus puertas o se declararon en quiebra y de estas únicamente 19 fueron franquicias, esto muestra la fortaleza de las franquicias tanto mexicanas como extranjeras.

Uno de los casos de éxito en cuanto a las franquicias mexicanas se destaca el de Diversiones Moy en el año de 1996; en ese año ya contaba con 60 unidades y se preparaba para entrar a Centroamérica.Para el años 2001, a las franquicias mexicanas se les consideraba como un modelo de negocios seguro y altamente redituable, según la AMF.

En el año de 2003 la tendencia brasileña de franquicias sociales llegó a México, con conceptos como guarderías para niños de padres de escasos recursos, capacitación técnica para jóvenes de escasos recursos, entre otros. En el 2007 el constante crecimiento del sector de las franquicias, provocó que se desarrollara el primer programa gubernamental al sector "El Programa Nacional de Feranquicias( PNF), el objetivo de este programa era apoyar la generación de nuevas empresas franquiciantes, de tal forma que todo aquel que quisiera adquiri una franquicia no tuviera tantas trabas, apoyo tambien con un porcentaje de la cuota incial para el desarrollo de un mayor número de franquicias, esto logro hacer que crezcan las cantidades de las mismas de un 750 en 2007 a 1,370 en 2012. Consecuentemente para el año 2008 México se ubicaba como el séptimo país generador de marcas de franquicias. Ya en el 2009 las franquicias con sentido social o impacto social se empezaron a incrementar en un número considerable (Feher F, 2015).

Basándose en lo anterior podemos afirmar que el sector de franquicias en México es altamente respaldado y apoyado teniendo como consecuencia el crecimiento, el gobierno federal sabe esto y muestra interés en continuar con el apoyo. Los expertos de 100 franquicias.com.mx declaran que las franquicias que triunfan y tienen mayor índice de inversión en México son las de la comida rápida y los restaurantes, con un $22 \%$ de franquicias de este giro operando en el país. El siguiente sector más importante es el de las franquicias de alimentos y bebidas con un $12 \%$ del mercado, finalmente el entretenimiento, turismo y recreación con un $7 \%$ del mercado. Estos sectores han mostrado un rendimiento importante con un crecimiento del $14 \%$ respecto al año pasado (2016).En la cuadro 1 se muestra el número de franquicias en México clasificada por los giros existentes según el reporte del 2013 hecho por la Asociación Mexicana de Fran- 
quicias.

Cuadro No.1 - Número de Franquicias en México por sector (2013)

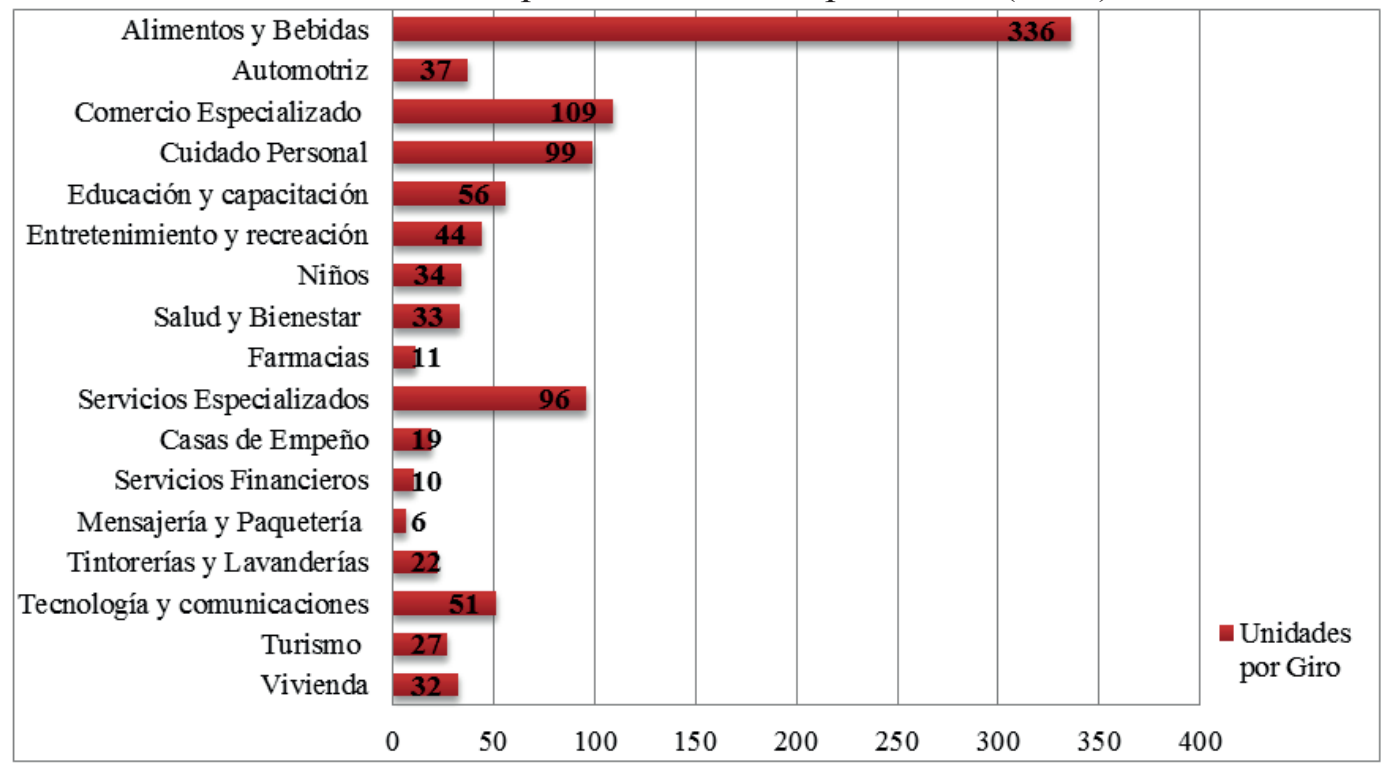

Fuente: AMF Estadísticas 2013

Asi como se puede identificar que el princial giro de franquicas en México es el de alimento y bebidas, en el cuador No.2 se pude observar como estan distribuidas las franquicias en México que lo hace por Regiones, y que la gran mayoría está ubicada en la región centro-sur, que es la que tiene el mayor número de franquicias con un $43 \%$, seguida de noreste $16 \%$ y occidente con $13 \%$.

Cuadro No.2 - Distribución de Franquicias Mexicanas por Región al 2013

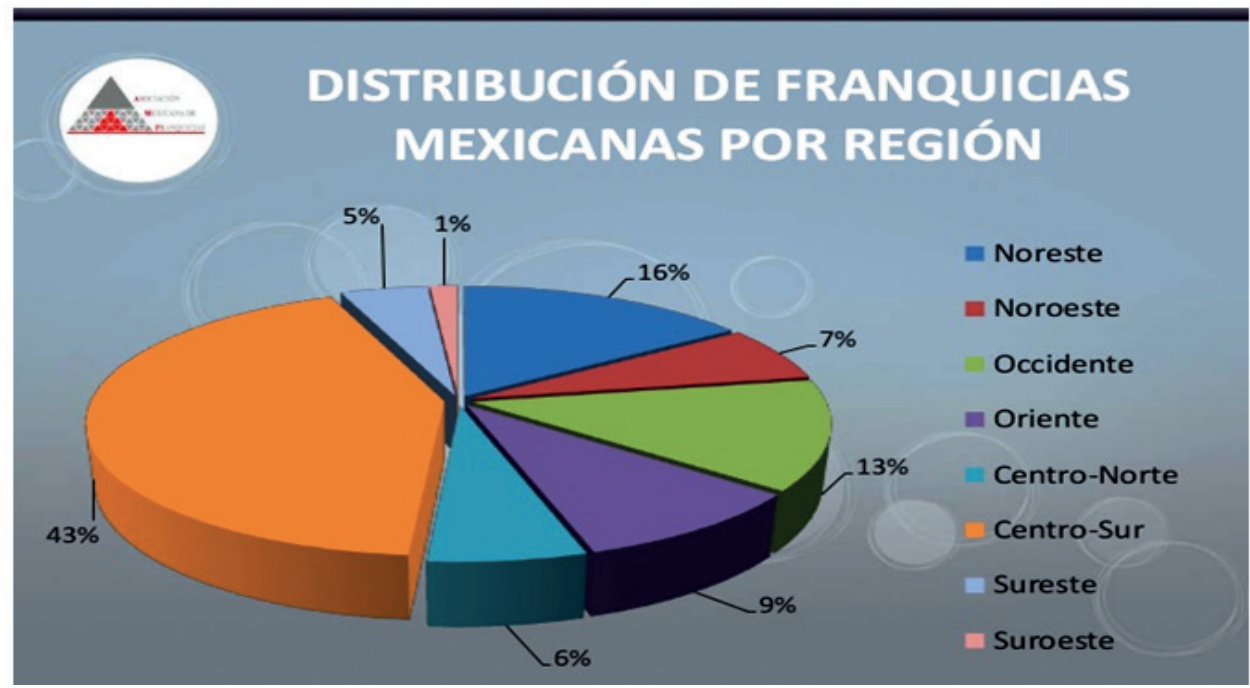

Fuente: Asociación Mexicana de Franquicias, 2014 
Se encontraron unos estadísticos del 2011 que prueban que el desarrollo de las Franquicias en México ha sido favorable para la economía mexicana ya que se puede observar en la figura No. 2 que se aumentaron más de 430,000 empleos del 2002 al 2010, así como los puntos de venta que pasaron de 25 mil a 45 mil. La importancia de esta modalidad se manifiesta al mostrar que el $95 \%$ de estos negocios seguían vivos al 5 to. año, y que se abría una nueva franquicia cada 6.25 hrs., pero sobre todo que generaban el 6\% del PIB en México.

Gráfica No. 1 -Desarrollo de las Franquicias en México al 2011

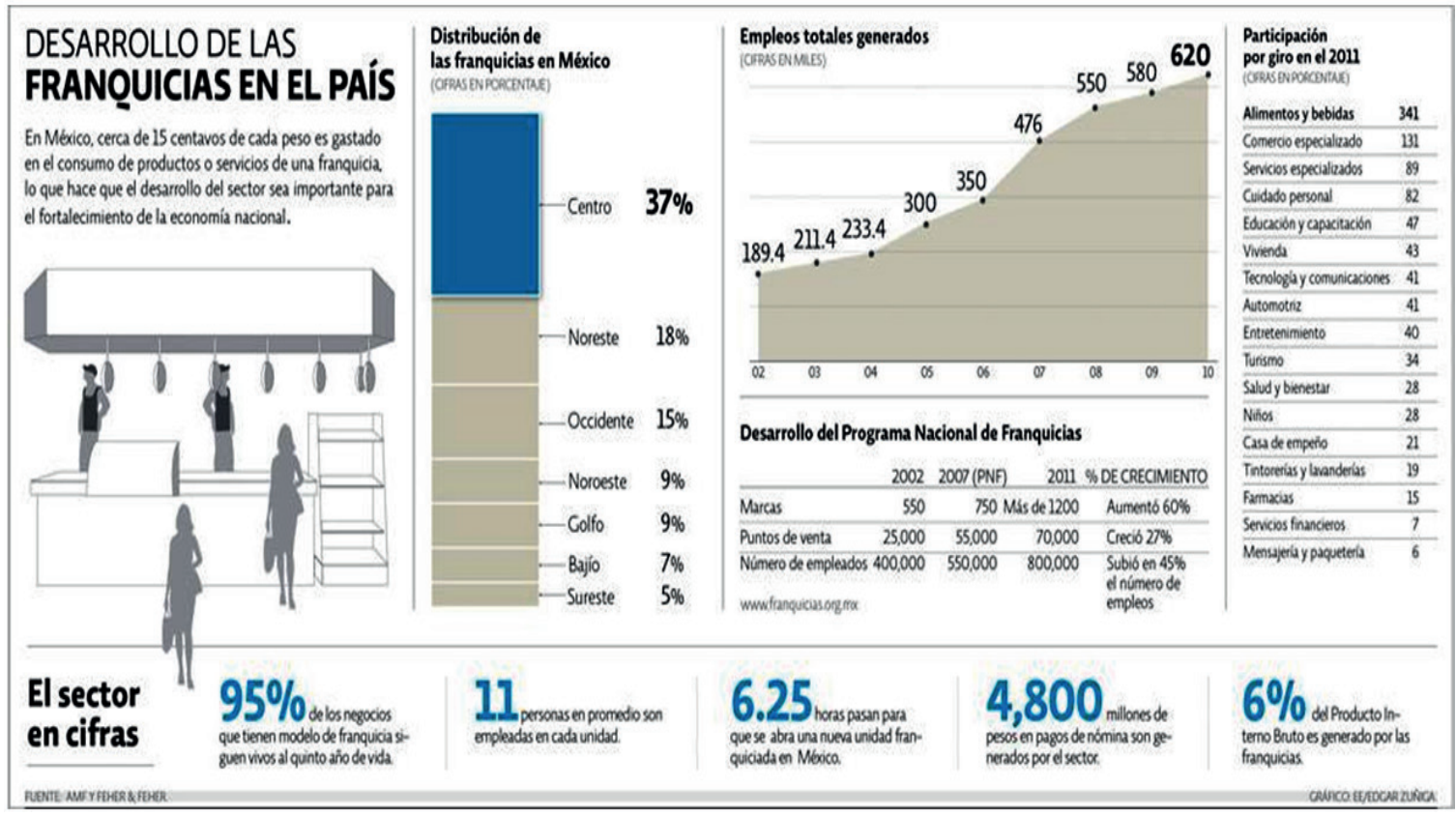

Fuente: El Economista Enero, 2012

Ahora analizando la información con relación a las franquicias en Nuevo León, los datos muestran que se han desarrollado con gran éxito los giros de alimentos y bebidas y cuidado personal (gráfica 1). En estos sectores se pueden mencionar algunos ejemplos de franquicias mexicanas como Mr. Fish, Las Alitas, Quick Shine, Excel Tours, Fango Spa, Ahal, Green Clean, Grupo Inmuebla, Super Salads, Tosta Rica y Viajes Alto. Todas las empresas mencionadas anteriormente que se han desarrollado a nivel local y se han expandido, lo que lo ha llevado a ocupar el tercer sitio de franquicias por Estado; en segundo lugar se coloca Guadalajara y el líder es la Ciudad de México. (González y Garza, 2015). 
Gráfica 2- Principales Giros de las franquicias en Nuevo León.

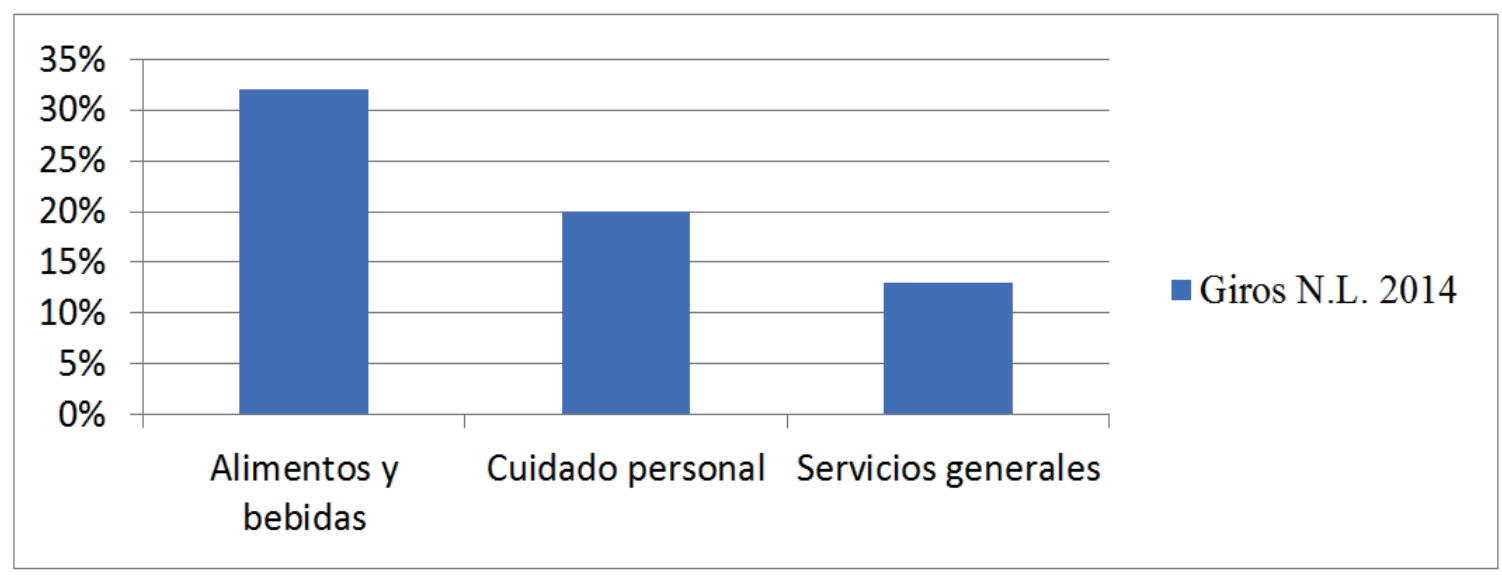

Fuente: Elaboración propia con datos de González y Garza 2015.

Cabe señalar que dentro de las principales 10 franquicias exitosas en Nuevo León (Cuadro No.3) se encuentran franquicias desarrolladas bajo el talento regiomontano y que han demostrado estar a la altura de las mejores en el mundo, ya que algunas de ellas ya están ubicados en otras partes del mundo, logrando así exportar su talento e innovación hacia otros lugares.

Tabla No.1 - Relación de Franquicias exitosas en el Nuevo León.

Rango y Nombre de Franquicia Exitosas en N.L.

\begin{tabular}{c|c|c|c}
\hline 1 & Mr. Fish & 7 & Green Clean \\
\hline 2 & Las Alitas & 8 & Grupo Inmuebla \\
\hline 3 & Quick Shine & 9 & Super Salads \\
\hline 4 & Excel Tours & 10 & Tosta Rica \\
\hline 5 & Fango Spa & 11 & Viajes Alto \\
\hline 6 & Ahal & &
\end{tabular}

Fuente: Elaboración propia con datos de González, Lourdes (2013)

\section{3.- MARCO TEÓRICO}

El mundo empresarial ha jugado un papel clave dentro de las relaciones y negocios internacionales puesto que además de contribuir a la expansión de lazos comerciales entre los países, se ha incrementado la expansión del comercio internacional. En la actualidad, la naturaleza global y cambiante de los negocios internacionales, como lo señalan las teorías de comercio y 
de inversión extranjera directa, aumenta la necesidad de interactuar con empresas extranjeras y de realizar incursiones en mercados diferentes al local para lograr que la organización sea perdurable.

Una manera de incursionar en estos mercados internacionales es través de las franquicias, que trae como ventaja hacer negocio fuera de su casa por cuestiones económicas. Existen varias teorías que fundamentan la ceración de la modalidad de Franquicias como las teorías de relaciones y desarrollo internacional, las que muestran el esquema de comercio exterior y la expansión vía inversión directa extranjera de los negocios internacionales.

En el caso de la Teoría de Inversión extranjera de Dunning (1988) se señala que si una empresa invirtiera en instalaciones de producción en el extranjero, deberá tener tres tipos de ventajas:

- Organización específica. Es el grado hasta el cual una empresa tiene, o puede lograr activos tangibles e intangibles no disponibles para otras empresas.

- Internalización. Parte de los mejores intereses de la empresa es emplear sus ventajas de propiedad específica (internalizar) en lugar de licenciarlas a dueños en el extranjero (externalizar).

- Localización. La empresa logrará utilidades al ubicar en el extranjero parte de las instalaciones de producción.

Otra Teoría que fundamenta la creación de franquicias es la Teoría Ecléctica de la Producción Internacional, proporciona una explicación sobre la elección que realizará la empresa internacional respecto a sus instalaciones productivas en el extranjero. La empresa debe contar con ventajas de ubicación y de propiedad para invertir en una planta en el extranjero. Invertirá en el lugar que rinda mayores utilidades para internacionalizar las ventajas monopolísticas (Dunning, 1982).

Estas y otras teorías explican porque las empresas se expanden internacionalmente exportando productos, otorgando licencia o franquicias, estableciendo alianzas estratégicas, realizando adquisiciones o construyendo subsidiarias nuevas con el 100\% del capital. Estas formas de entrar al mercado internacional ofrecen ventajas y desventajas, centrándonos en las franquicias podemos mencionar que es una forma de licenciamiento en el que una empresa celebra un contrato con otra para operar diferentes negocios, al amparo de una marca establecida y de acuerdo con reglas específicas. Éstas permiten al franquiciatario vender bienes o servicios bajo una marca altamente publicitada y un conjunto cuidadosamente desarrollado, probado y controlado de procedimiento de ventas (Rugman y Hodgetts, 1997: 558).

Estas estrategias de entrada en los mercados exteriores son la forma en que las empresas desarrollan sus actividades en el exterior. La elección de la forma más adecuada dependerá 
principalmente de la intensidad de la penetración que se quiera alcanzar en el país de destino, es por ello que se pretende definir los factores que se deben considerar para que la empresa puede optar en atender todos sus mercados tanto nacional como internacional desde el país de origen, hasta situar sus actividades de valor en todos los países de destino.

Para esta investigación se trabajará exclusivamente con las franquicias como modelo de entrada en los negocios internacionales. Tiene diversos beneficios para los países ya que no sustituyen a las exportaciones ni exportan empleos, y desde un punto de vista de país receptor las franquicias generan pocas salidas de divisas, de consumos locales, por lo que la mayoría de ganancias permanecen en el país destino (Castañón, 2007) .

\section{4.- MARCO CONCEPTUAL DE LAS FRANQUICIAS}

Uno de las primeras definiciones de las franquicias es que se considera como un contrato que cubre una amplia gama de prestaciones de servicios, suministro de bienes, cesión de nombre comercial o marca, por parte del franquiciador y abono de un porcentaje de los ingresos, por parte del franquiciado (Santesmases).

Para Steven Raab son un sistema de comercialización, un método para distribuir bienes y servicios a los consumidores. Que concierne a dos niveles de personas: el franquiciador, quien desarrolla el sistema y le presta su nombre o su marca registrada y el franquiciatario, quien adquiere el derecho de operar el negocio bajo el nombre o la marca registrada del franquiciador (Raab, 1991).

Por lo tanto la franquicia se basa en una estructura legal donde el franquiciante (dueño de la franquicia) es quien otorga la licencia para el uso del nombre, sistema de operaciones y soporte de una marca y el know how para operarla al franquiciatario (persona física o moral que la compra). Esto significa que, por determinado tiempo, el franquiciatario utilizará esa marca y manejará un negocio de manera uniforme al resto de las unidades franquicias anteriormente. A pesar de que el franquiciatario tiene la licencia para operar el negocio, éste no es dueño de la marca, o del mercado, o del sistema de operaciones o de soporte, pues éstos le pertenecen al franquiciante. Sin embargo, la ventaja de este modelo es que, a cambio de una inversión, se obtienen los beneficios de trabajar con un producto o servicio ya probado y con bajo riesgo" (Entrepreneur, 2008) .

Otras ventajas de las franquicias es que cuentan con un estudio de mercado para determinar una buena ubicación, de acuerdo a la orientación, y además proporcionan la experiencia del franquiciante. Se convierte en un vínculo de inversión privado que permite compartir las experiencias del éxito de empresarios que ya han recorrido la curva de aprendizaje propia de cualquier negocio, una estrategia de negocio para ganar nuevos clientes y conservar los ya exis- 
tentes, Además se recibe capacitación para operarlo y cuentan con una marca que respalda el producto o servicio que ofrecen (Rodríguez, 2009).

Por consiguiente, en esta investigación el término franquiciante o franquiciador es identificado como la persona que cede los derechos y cobra por tal acción, otorga la licencia de uso de una marca con el derecho a distribuir ciertos productos o a explotar con cierta exclusividad, una empresa o negociación mercantil de bienes o de servicios, en ambos caso, mediante la transmisión de conocimientos técnicos y el uso de la marca y nombre comercial, a cambio de una contraprestación generalmente ligada a los resultados de la operación de la negociación." (ARCE Gargollo, op.cit., supra 78). La otra persona que participan en el sistema de la franquicia es el franquiciatario, donde Aldave (2010) lo define como la persona que adquiere el sistema operativo mediante el pago de regalías y recibe los conocimientos que el franquiciante le confía para dar al negocio franquiciado los estándares de calidad del producto o servicio que ofrece la franquicia maestra.

Para formalizar legalmente las franquicias, se requiere contrato de franquicia que está definido en México por el Artículo 142 de la Ley de la Propiedad Industrial que dice existirá franquicia, cuando con la licencia de uso de una marca, otorgada por escrito, se transmitan conocimientos técnicos o se proporcione asistencia técnica, para que la persona a quien se le concede pueda producir o vender bienes o prestar servicios de manera uniforme y con los métodos operativos, comerciales y administrativos establecidos por el titular de la marca, tendientes a mantener la calidad, prestigio e imagen de los productos o servicios a los que ésta distingue.

\section{5.- MARCO TEÓRICO DE LOS FACTORES PROPUESTOS}

En cuanto al marco teórico de los factores propuestos se definen de la siguiente manera:

Asistencia técnica: Uno de los elementos importantes durante la operación de una Red de Franquicias, es la asistencia técnica, cuyo objetivo principal es: asesorar, controlar y supervisar la imagen y operación del sistema de franquicias, en las unidades incorporadas a la red, de acuerdo a las normas, procedimientos y métodos determinados por el Franquiciante.

El Franquiciante está obligado a realizar la asistencia técnica, a favor de sí mismo y de los Franquiciatarios que cumplen con las políticas y procedimientos del sistema de franquicias y que podrían verse afectados por actos o formas dañinas de quienes no cumplen con dichas políticas y procedimientos.

La finalidad de la asistencia técnica debe ser más concebida con la prevención que con la penalización por las posibles desviaciones de las políticas y procedimientos, sirviendo también como vía de comunicación entre el Franquiciante y los Franquiciatarios a través de las sugerencias que éstos pueden plantear acerca de cualquier aspecto relacionado con la operación diaria

Revista Política, Globalidad y Ciudadanía, Vol. 6. No. 12, Julio - Diciembre 2020, Universidad Autónoma de Nuevo León, Monterrey, México, ISSN 2395-8448. 246-264. http://revpoliticas.uanl.mx/index.php/RPGyC/article/view/164 
de la Franquicia.

Relación de partes: Es cuando la relación en una franquicia busca que ambos participantes puedan tener tanto un beneficio económico, como una sana relación interpersonal y que permita dar mayor apoyo en los canales de distribución. Sobre la relación entre franquiciante y franquiciado, Schul, Little, y Pride (1985) muestran que la satisfacción del franquiciado está relacionada con la forma en que este percibe la calidad de las interacciones con el franquiciador, la calidad de su apoyo operativo, el atractivo de la estructura de recompensas, la equidad y la autonomía de la relación. Resultados similares fueron encontrados por Lewis y Lambert (1991, citado en Diez, Martín, Navarro, Rondán 2005) que afirma que los franquiciados se sienten satisfechos si consideran que el éxito se debe a que el franquiciador lo apoya, (Guerrero Banderas, M. E., Armenteros Acosta, M. D. C., \& Elizondo, M., 2014).

Se destaca que la calidad de la relación no depende solo de la simpatía sino de que la marca esté bien posicionada gracias al esfuerzo de ambas partes y de que los resultados en términos de ganancias sean buenos (Bermúdez, 2001). La lealtad del franquiciatario también es resultado de una buena relación ya que si está contento es seguro que recomiende a otros interesados su sistema de franquicia, (Guerrero Banderas, M. E., y otros, 2014).

La relación franquiciador y franquiciado, es necesario que ambas partes desarrollen confianza y compromiso mutuos para que esa relación se prolongue a lo largo del tiempo y sea más rentable, (Guerrero Banderas, M. E., y otros, 2014).

Antigüedad de la franquicia: La antigüedad de la existencia de la franquicia es el tiempo que lleva trabajando en ella, mientras más tiempo lleva, más experiencia se tienen y eso ayudaría a poder apoyar con mayor conocimiento a los futuros franquiciatarios.

Se desglosa en tres tipos de antigüedades: la de la empresa en el mercado, de la firma bajo el formato de Franquicia y de la marca operando en México como mercado local.

La experiencia de tiempo con el uso de esa franquicia le da el modo de conocer algo inmediatamente antes de todo juicio formulado sobre lo aprehendido. Es la respuesta interna y subjetiva de los trabajadores ante cualquier contacto directo o indirecto con alguna práctica, política o procedimientos de gestión de personas y que eso les da la experiencia adquirida.

Condiciones contractuales: Son todos los requisitos que se deben de cumplir con el franquiciatario, tanto en los procesos de inicio y permanencia del contrato, como en la calidad y atención de la franquicia. La relevancia estratégica del contrato de franquicia y su gran implementación a nivel mundial se presenta porque, con el derecho de uso, la explotación de las marcas y el conjunto de procedimientos del know how, el franquiciado puede beneficiarse de la popularidad del del negocio del franquiciante, reconocido en el mercado; con esto, el franquiciado no tiene la carga de invertir mucho tiempo, ni recursos económicos en dar a conocer 
la marca, lo que disminuye, en gran medida, los riesgos del nuevo empresario. Ambas partes, tanto el franquiciante como el franquiciado, mediante el contrato de franquicia, buscan la colaboración mutua (Soto, J. D. U. ,2012).

Quien conceda una franquicia deberá proporcionar a quien se la pretende conceder, previamente a la celebración del convenio respectivo, la información relativa sobre el estado que guarda su empresa, en los términos que establezca el reglamento de esta Ley de la Propiedad Industrial artículo 142, (Guerrero Banderas, M. E., y otros, 2014).

Renombre de la marca: Es cuando una franquicia tiene éxito en el mercado, porque tienen muchas franquicias y/o por la calidad de su franquicia con los servicios y productos que ofrece. La marca es utilizada para reconocer un producto en un sistema de distribución en un principio para después adquirir un valor determinado en el mercado que puede ofrecerse. La creación de valor está estrechamente vinculada a la transmisión de intangibles, ya que el franquiciador cede a los franquiciados unas capacidades de gestión y el respaldo de un nombre de marca que permite que persona sin experiencia previa puedan dirigir un negocio con éxito. Una de las claves del éxito comercial de la franquicia se encuentra en que la marca de la franquicia proporcione certidumbre al consumidor lo que hace que este decida comprar, y también influye la publicidad que los proveedores hagan de sus productos. En el caso de la franquicia, el franquiciador hace una publicidad internacional y nacional; da valor a la marca, mientras que los franquiciados pueden hacer una publicidad local y seguir los lineamientos del franquiciador para garantizar una calidad y unos precios uniformes, (Guerrero Banderas, M. E., y otros, 2014).

\section{6.- RESULTADOS}

En este artículo se determinó la confiabilidad del instrumento para medir mediante el Coeficiente alfa de cronbach utilizando el SPSS.

El Alfa de Cronbach es considerada un estimador estable de la confiabilidad calculada por mitades de una prueba. Es importante este coeficiente porque permite analizar el alcance con que los ítems del instrumento miden el constructo de manera coherente. Su valor fluctúa entre $0.00 \mathrm{y}+1.00$. Los valores que se recomiendan para estos índices son entre $0.70-0.90$. Valores bajos indican que el instrumento no muestra consistencia ante diferentes condiciones de aplicación, y su valor más alto refleja un mayor grado de congruencia interna (Ortega, Y. G. ,2008).

Existen dos requisitos que por su relevancia son fundamentales en un instrumento de medición, estos son: confiabilidad y validez .En el campo de las ciencias sociales, se consideran estos dos conceptos como aspectos claves de la llamada "solidez psicométrica" del instrumento. En este artículo se ocupó fundamentalmente de la confiabilidad y específicamente del coeficiente del alfa de Cronbach, con lo que se pretende calcular la correlación de cada reactivo 
o ítem con cada uno de los otros, teniendo como resultando una gran cantidad de coeficiente de correlación, (Virla, M. Q. ,2010).

Por consiguiente, para que se hable de que el instrumento es idóneo, y que se pueda utilizar con toda la confianza se requiere que cumpla con los dos requisitos: confiabilidad y validez, (Ortega, Y. G. ,2008).

Al lanzar los datos estadísticos se obtuvo como resultado, para el cálculo del coeficiente alfa de Cronbach, la información detallada en el siguiente cuadro No.4 :

Tabla No.2 - Cálculo del coeficiente alfa de Cronbach

\begin{tabular}{l|c} 
Reliability Statistics & Cronbach's Alpha \\
\hline Asistencia técnica & .827 \\
\hline Relación de partes & .575 \\
\hline Antigüedad de la marca & .689 \\
\hline Condiciones contractuales & .749 \\
\hline Renombre de marca & .562
\end{tabular}

Fuente: Elaboración propia.

En el alfa de Cronbach en el caso de la relación de las partes obtenemos un 0.575 que si bien sabemos no es el adecuado, es debido a que en las correlaciones de las preguntas realizadas en esta dimensión, a la pregunta de "para lograr la uniformidad en todos los establecimiento es necesario llevar un buen control" obtuvimos una correlación muy baja y de sentido negativo contrastada con la capacitación que ofrece la franquicia a los franquicitarios. Esta situación nos demerita el 0.70 que deberíamos observar en este estadístico; sin embargo consideramos importante conocer la percepción del encuestado en el sentido de saber que tan necesario es que el fraqnuiciatrio lleve un buen control.

De igual forma en el caso del Renombre de la marca donde se obtiene un 0.562, se observa que también se encuentra por debajo del 0.70 , se identificó que la pregunta "las franquicias son una alternativa de negocio para cualquier emprendedor" no es de gran relevancia ;sin embargo consideramos importante saber si los futuro empredendor/franquiciatario ve este modelo de negocio como una alternativa para emprender un nuevo proyecto.

En el caso de las dimensiones Asistencia Técnica, Antigüedad de la Marca y Condiciones contractuales no presentan la misma situación anterior ya que los valores de confiabilidad son adecuados ya que en los tres se observan valores por encima del .70 requerido. 
Tabla No.3- Correlaciones de variables

\begin{tabular}{|c|c|c|c|c|c|c|c|}
\hline \multicolumn{8}{|c|}{ Correlations } \\
\hline & & EXITOFRAN & ASISTECNICA & RELPARTES & ANTIMARCA & $\begin{array}{c}\text { CONDCONT } \\
\text { RA }\end{array}$ & RENMARCA \\
\hline \multirow[t]{6}{*}{ Pearson Correlation } & EXITOFRAN & 1.000 & -.100 & .256 & .320 & .155 & .403 \\
\hline & ASISTECNICA & -.100 & 1.000 & .430 & .033 & .324 & .272 \\
\hline & RELPARTES & .256 & .430 & 1.000 & .358 & .473 & .532 \\
\hline & ANTIMARCA & .320 & .033 & .358 & 1.000 & .344 & .530 \\
\hline & CONDCONTRA & .155 & .324 & .473 & .344 & 1.000 & .600 \\
\hline & RENMARCA & .403 & .272 & .532 & .530 & .600 & 1.000 \\
\hline \multirow[t]{6}{*}{ Sig. (1-tailed) } & EXITOFRAN & . & .313 & .103 & .055 & .225 & .021 \\
\hline & ASISTECNICA & .313 & . & .014 & .436 & .053 & .089 \\
\hline & RELPARTES & .103 & .014 & . & .036 & .007 & .003 \\
\hline & ANTIMARCA & .055 & .436 & .036 & . & .043 & .003 \\
\hline & CONDCONTRA & .225 & .053 & .007 & .043 & . & .001 \\
\hline & RENMARCA & .021 & .089 & .003 & .003 & .001 & . \\
\hline \multirow[t]{6}{*}{$\mathrm{N}$} & EXITOFRAN & 26 & 26 & 26 & 26 & 26 & 26 \\
\hline & ASISTECNICA & 26 & 26 & 26 & 26 & 26 & 26 \\
\hline & RELPARTES & 26 & 26 & 26 & 26 & 26 & 26 \\
\hline & ANTIMARCA & 26 & 26 & 26 & 26 & 26 & 26 \\
\hline & CONDCONTRA & 26 & 26 & 26 & 26 & 26 & 26 \\
\hline & RENMARCA & 26 & 26 & 26 & 26 & 26 & 26 \\
\hline
\end{tabular}

Fuente: Elaboración propia.

Como se muestra en la tabla no. 3 de correlaciones podemos observar que los valores más altos se presentan en las dimensiones de : Renombre de la Marca con un valor de $\mathrm{R}=0.403$; $\mathrm{y}$ en la dimensión de Antigüedad de la Marca con un valor de $\mathrm{R}=0.320$. En ese sentido obteniendo el coeficiente de determinación R2, observamos que para la primera de las dimensiones que es el renombre de la marca explica en un $16 \%$ el éxito de la franquicia ,mientras que la dimensión de la antigüedad de la marca lo explica en un $10 \%$ que aunados explican en un $26 \%$ que una franquicia sea exitosa.

Como contraste encontramos que la dimensión de asistencia técnica es el factor que aporta en menor cantidad y curiosamente observamos un coeficiente de correlación negativo con respecto al éxito de la franquicia.

Tabla No.4- Resumen del modelo

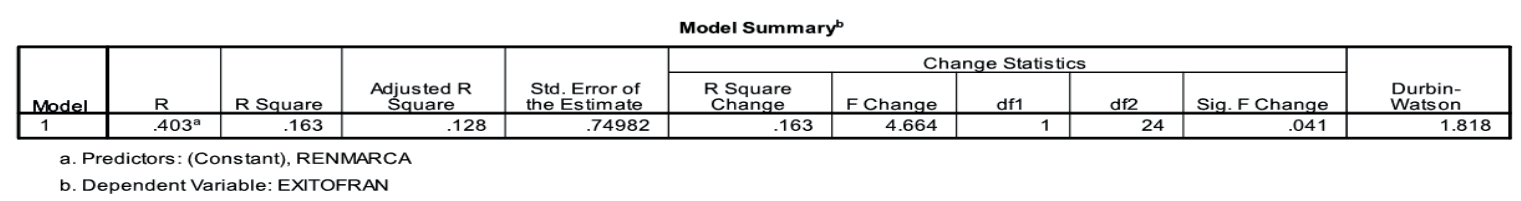

Fuente: Elaboración propia.

Revista Política, Globalidad y Ciudadanía, Vol. 6. No. 12, Julio - Diciembre 2020, Universidad Autónoma de Nuevo León, Monterrey, México, ISSN 2395-8448. 246-264. http://revpoliticas.uanl.mx/index.php/RPGyC/article/view/164 
Tabla No.5- Análisis de Varianza

\begin{tabular}{|rl|r|r|r|r|r|}
\hline \multicolumn{1}{|c|}{} & \multicolumn{1}{c|}{$\begin{array}{c}\text { Sum of } \\
\text { Squares }\end{array}$} & df & Mean Square & F & Sig. \\
\hline 1 & Regression & 2.622 & 1 & 2.622 & 4.664 & $.041^{\mathrm{a}}$ \\
& Residual & 13.493 & 24 & .562 & & \\
& Total & 16.115 & 25 & & & \\
\hline
\end{tabular}

a. Predictors: (Constant), RENMARCA

b. Dependent Variable: EXITOFRAN

Fuente: Elaboración propia.

Con base en las tablas No. 4 y No.5 anteriores ratificamos la relevancia de la dimensión renombre de la marca; porque presenta un coeficiente de determinación de $16 \%$ y por otro lado en la tabla no. de ANOVA observamos un nivel de significancia de 0.41 que es menor a nuestro nivel de significancia de 0.05 . Esto constata que nuestra variable independiente de renombre de la Marca influye de manera importante en nuestra variable dependiente que es el éxito de la franquicia.

Tabla No.6 Regresión

\begin{tabular}{|c|c|c|c|c|c|c|c|c|c|c|c|}
\hline \multicolumn{12}{|c|}{ Coefficients $^{\mathrm{a}}$} \\
\hline \multirow[b]{2}{*}{ Model } & & \multicolumn{2}{|c|}{ Unstandardized Coefficients } & \multirow{2}{*}{$\begin{array}{c}\text { Standardized } \\
\text { Coefficients } \\
\text { Beta }\end{array}$} & \multirow[b]{2}{*}{$t$} & \multirow[b]{2}{*}{ Sig. } & \multicolumn{3}{|c|}{ Correlations } & \multicolumn{2}{|c|}{ Collinearity Statistics } \\
\hline & & B & Std. Error & & & & Zero-order & Partial & Part & Tolerance & VF \\
\hline 1 & (Constant) & 1.847 & 1.131 & & 1.633 & .116 & & & & & \\
\hline & RENMARCA & .554 & .256 & .403 & 2.160 & .041 & .403 & .403 & .403 & 1.000 & 1.000 \\
\hline
\end{tabular}

a. Dependent Variable: EXITOFRAN

Fuente: Elaboración propia.

En la tabla No.6 de regresión anterior solo se podría aplicar si se buscara hacer un pronóstico, lo cual no es nuestro caso.

Ecuación de regresión:

$$
Y=\boldsymbol{m} \boldsymbol{b}+\boldsymbol{a}
$$

$Y=1.847 x+0.554$ 


\section{7.- CONCLUSIONES}

Las conclusiones derivadas del presente trabajo de investigación sobre los factores que impulsan el uso de franquicias exitosas en el estado de Nuevo León, nos muestra que en los últimos años las franquicias han ido incursionado en la economía tanto a nivel nacional como internacional lo que ha motivado el interés empresarial y académico por las mismas. Por tal situación cada vez son más los interesados en conocer sobre las franquicias desde diferentes líneas de investigación. Dado que se estima que más de 800 empresas son franquicias operando que comenzaron su expansión a nivel internacional con un adicional de 100 cada año.

En esta investigación fue relevante buscar la forma de obtener por medio de los franquiciadores que operan en México, aquellos factores que podrían impulsar el uso de franquicias exitosas, esto para poder promoverlos entre las PYMES. Utilizando un modelo de investigación con un enfoque cuantitativo, se unió la información obtenida y se concluyó que los franquiciadores coinciden en que se debe tener una buena "relación de las partes y condiciones contractuales" , lo cual implica una buena comunicación para resolver y evitar malos entendidos en la franquicia.

También señalaron que es muy importante brindar "Asistencia técnica" o manuales de procedimientos detallados para así ofrecer un mejor servicio con productos de calidad. Permitiendo así una "renombre de la marca", que como todo empresario busca siempre tener.

Con los datos capturados del instrumento cuantitativo se obtuvieron las tablas de correlaciones que nos arrojaron que los valores más altos se presentan en las dimensiones de " Renombre de la Marca" con un valor de $\mathrm{R}=0.403$ o un $16 \%$, lo que representa una un correlación positiva al éxito de una franquicia ; y en la dimensión de "Antigüedad de la Marca" con un valor de $\mathrm{R}=0.320$, ósea un $10 \%$, explicando así que las dos juntas aportan un $26 \%$ a que una franquicia sea exitosa.

Como contraste encontramos que la dimensión de "Asistencia técnica" es el factor que aporta en menor cantidad y curiosamente observamos un coeficiente de correlación negativo con respecto al éxito de la franquicia.

Por lo tanto en base a lo anterior ratificamos la relevancia de la dimensión "Renombre de la marca"; porque presenta un coeficiente de determinación de $16 \%$ y un nivel de significancia de 0.041 que es menor a nuestro nivel de significancia de 0.05 . Esto constata que nuestra variable independiente de renombre de la Marca influye de manera importante en nuestra variable dependiente que es el éxito de la franquicia.

Por lo tanto al revisar los datos obtenidos de los cuestionarios (cuantitativo) y uniendo así la información de los franquiciadores se identifica que todos coinciden en que el "Renombre de la Marca" influye de manera importante en nuestra variable dependiente que es el éxito de la 
franquicia, esto reflejado con un aumento en unidades.

\section{REFERENCIAS}

Aguirre Pesantes, L., Arenas Reátegui, E., Portal Arboleda, J., \& Villanueva Paz, F. (2006). Factores de éxito en las franquicias: un estudio exploratorio.

Aldave, A., \& Cristina, M. (2010). Las franquicias en México en 1999 y 2007. Contaduría y Administración, (230).

Anónimo, (2017). Descubre qué tipos de franquicias triunfan en México Consultado en: http:// www.100franquicias.com.mx/Noticias/2017-02-15-Descubre-que-tipos-de-franquiciastriunfan-en-Mexico.htm

Arias, E.E. M.(2010). Modelo De Franquicia Como Opción De Emprendimiento. Contribuciones a la Economía, (2010-11).

Castañón, R., \& Solleiro, J. L. (2007). Los instrumentos de política industrial y la competitividad de las pequeñas y medianas empresas mexicanas del sector de alimentos. Innovación y desarrollo tecnológico, 1, 109-135.

D Dunning, J. H. (1982). Explaining the international direct investment position of countries: towards a dynamic or developmental approach. In International Capital Movements (pp. 84-121). Palgrave Macmillan, London.unning, J. H., \& Pearce, R. D. (1981). The world's largest industrial enterprises. Gower Publishing Company, Limited.

Díez, E.C., Rondán, F.J. y Navarro, A. (2004): Research on Franchising, en Global Business: coping with uncertainty, I.M.D.A. (International management development research yerbook), Edited by Kaynak, E. y Harcar, T. Maastricht (Holanda), pp. 430-437.

Dunning, J. H. (1988). Explaining international production. Londes y Boston. Unwin Uyman

Erramilli, M. K.; Agarwal, S. Y Dev, C. (2002): Choice between Non-equity Entry Modes: An Organizational Capability Perspective, Journal of International Business Studies, No. $33,223-243$

Feher, F. (2015). Historia de las franquicias en México. De Entrepreneur Consultado de: https://www.entrepreneur.com/article/268970

Fernández, M. y Martín, J. (2005): «La confianza y el compromiso como factores clave de éxito en las relaciones comerciales. Una aplicación empírica en el sistema de franquicia», Revista Europea de Dirección y Economía de la Empresa, Vol. 15. No. 1, pp. 77-100. 
Guerrero Banderas, M. E., Armenteros Acosta, M. D. C., \& Elizondo, M. (2014). Desarrollo Estratégico De Las Franquicias Mexicanas: Estudio Empírico En La Comarca Lagunera, México (Strategic Development of Mexican Franchises Empirical Study in the Laguna Region, México). Revista internacional administración \& finanzas, 7(6), 45.

INEGI, C. E. (2009). Datos estadísticos de las empresas. Obtenido de http://www. inegi. org. Mx/prod_serv/contenidos/espanol/bvinegi/productos/censos/economicos/1999/general/ resumen. pdf. En febrero de. Instituto nacional de estadísticas y geografía (INEGI), (2012): Recabado de: http://www.inegi.org.mx/prod_serv/contenidos/espanol/bvinegi/ productos/metodologias/ENOE/ENOE2012/franquicias/franquicias_2012.pdf

Johanson, J., \& Wiedersheim $\square$ Paul, F. (1975). The internationalization of the firm-four swedish cases 1 . Journal of management studies, 12(3), 305-323.

Lamb, C.; Joe H. \& Carl MC. (2006). Fundamentos de marketing (4⿳a ed.). España: Thomson

Mosquera, F. (2010). La franquicia una estrategia de crecimiento empresarial. Revista MBA Eafit, 1, 70-85.

Murciano,J.M. (2013) "Factores de éxito en franquicia". Consultado de: "http://www. t4franquicias.com/factores-de-exito-en-franquicia/

Ortega, Y. G. (2008). Instrumento Cuidado de comportamiento profesional: validez y confiabilidad. Aquichan, 8(2), 170-182.

Raab, S. S., \& Matusky, G. (1991). Franquicias: cómo multiplicar su negocio. Limusa.

Rodríguez Garay, R. (2009). La cultura organizacional. Un potencial activo estratégico desde la perspectiva de la administración. Invenio, 12(22).

Rugman, A. y Hodgetts, R. (1997). Negocios Internacionales. (p.485). México: Ed. McGraw Hill.

Sallenave, J. (1985). Gerencia y planeación estratégica. Bogotá: Norma.

Schul, P. L., Little, T. E., \& Pride, W. M. (1985). Channel climate: Its impact on channel members' satisfaction. Journal of Retailing.

SE, (2014). "Fondo nacional del emprendedor" recuperado de: http://\|ll.sisteŵaewpdeŶdedod. god'.ŵwž en fecha 29 mayo del 2014

Sherman, A. J. (1993). The franchising handbook. Amacom. 
Soto, J. D. U. (2012). Franquicias Nacionales: Factores de éxito y fracaso. Economía y Sociedad, $17(42), 9-31$.

Ulloa, D. (2012). Franquicias Nacionales: Factores de éxito y fracaso. Economía y Sociedad, Vol. 42, pp. 9-31. ISSN: 1409-1070.

Villanueva, C. A. F., \& Villegas, J. B. G. (2015).La Internacionalización De Las Franquicias Mexicanas: El Efecto de las Variables Organizacionales Sobre El Grado De Internacionalización.

Virla, M. Q. (2010). Confiabilidad y coeficiente Alpha de Cronbach. Telos: Revista de Estudios Interdisciplinarios en Ciencias Sociales, 12(2), 248-252. 